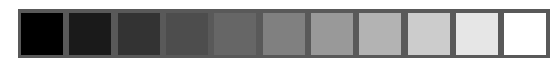

\title{
Edgar Morin, um pensador para o Brasil
}

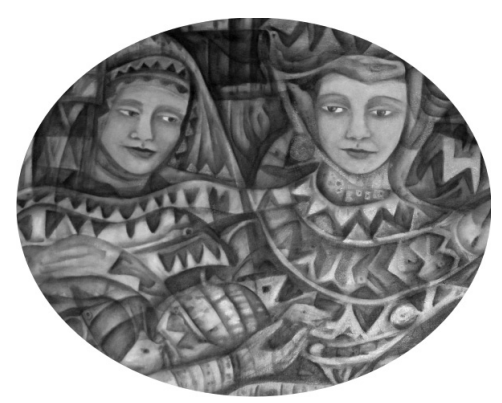

Edgard de Assis Carvalho*

\section{Resumo}

O autor oferece uma visão pessoal da trajetória intelecutal do antropólogo francês Edgar Morin. Mostra como foram elaborados, ao longo desse percurso, os pressupostos do pensamento complexo. O reconhecimento da relevência de sua obra para o entendimento da América Latina e do Brasil tem se tornado cada vez mais evidente. A identificação do autor com Morin vai além do aspecto intelectual, como mostram suas participações em três homenagens realizadas em Paris e em São Paulo.

Palavras-chave: Edgar Morin. Complexidade. Antropologia

\section{Abstract}

The author offer a personal vision about the french anthropologist Edgar Morin and her intelectual biography. Show how the principles of the complex thought was elaborated. The relevance of her oeuvre for the knowledge of Latin America and Brazil has been more and more evident. The auhtor admiration about Morin goes beyond the intelectual side such as show her presence in three homages at Paris and São Paulo.

Keywords: Edgar Morin. Complexity. Anthropology.

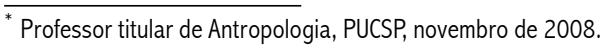


A Antropologia fundamental de Edgar Morin coloca o homem em seu devido lugar. Marcado por constante auto-organização, o sujeito é simultaneamente biológico e cultural. Admitir esse pressuposto implica assumir a animalidade como marca fundamental de qualquer ser vivo, bactéria, ameba, homem. Autônomo, o sujeito reorganiza o ecossistema que o rodeia, produz saberes, acumula experiências, desilusões, utopias, afetos.

Esse processo não é mais exclusivo de primatas humanos, pois gorilas, orangotangos, chimpanzés, bonobos estabelecem modalidades de convivência ética e refinados padrões sexuais não ligados à procriação, como se a sexualidade fosse feita para regular a violência e desejo. Se esse estilo fosse consumado pelos humanos, a maior parte dos problemas sexuais seriam melhor equacionados, com mais prazer e menos repressão.

Destituídos de linguagem articulada, primatas não humanos constroem padrões, transmitem códigos de conduta e ética, criam cultura, se radicalizarmos o conjunto de suas performances com este nome. Talvez ainda não possuam exata consciência da morte, marca distintiva da humanidade. Como nós, nutrem-se de acasos, tensões, contradições, erros.

Com poucas exceções, as ciências humanas resistem a admitir esse fato perturbador. Continuamos antropocêntricos e narcísicos, acreditamos demais em nossa força de criação e destruição. Portadoras de uma tecnosfera comandada por máquinas, robôs e clones, as sociedades humanas, líqüidas, produzem uma organização social inautêntica e infeliz, que absolutiza a dominação predatória da natureza, a destruição da ecosfera e amplia o espectro das intolerâncias e cinismos econômicos, políticos, étnicos.

Esses pressupostos constitutivos da complexidade são sistematizados a partir dos anos $60 \mathrm{com}$ as análises da morte, da magia do cinema. Em qualquer filme, essa circulação se atualiza peremptoriamente, como se estivéssemos diante de um operador simbólico que aciona emoções incontidas, medos arcaicos, desejos inconfessáveis, ódios reconhecidos. O cinema quebra o quadro espaço-temporal objetivo do cinematógrafo. Capta os objetos sob ângulos de visão inusitados, submete-os a prodigiosas ampliações, confere-lhes movimentos irreais". (MORIN, 1997, p. 144).

Como o cinema, a morte constitui um fenômeno social total, dada a mutidimensionalidade de suas causas e conseqüências. Tudo que foi produzido sobre

12 Somanlu, ano 8, n. 2, jul./dez. 2008

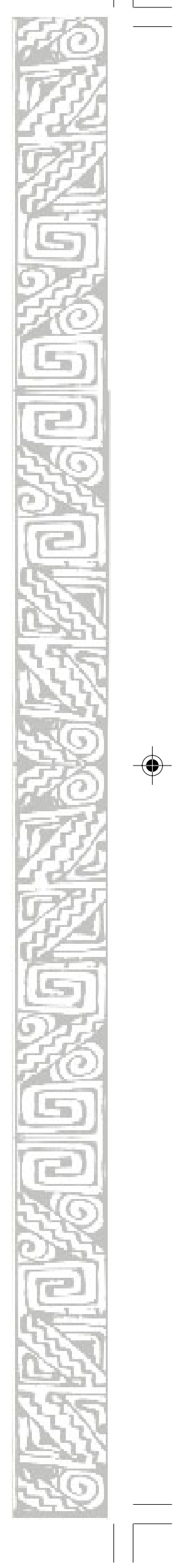


ela, a partir do século 19, acabou por transformá-la numa noz oca. Idealizada pelo romantismo, niilizada pela ciência, a consciência ocidental acabou por escanteá-la numa solidão irreversível, abandonada à sua própria sorte. A reforma da morte (MORIN, 1951) exige que a inevitabilidade da mortalidade e o sonho da imortalidade sejam substituídos pela ambigüidade da amortalidade, condição indeterminada na qual o momento final de qualquer ser vivo não é visto como exclusão, solidão, abandono, degradação, mas como sintoma de transformação, mutação, metamorfose para outros estados do ser.

O cinema, afirma Morin, desvenda e desenvolve as estruturas intelectuais da participação e, simultaneamente, as estruturas participativas e dissipativas da inteligência; tal como a teoria da magia e da afetividade, aclara também a teoria da formação e do desenvolvimento das ideias (MORIN, 1997, p. 210). Exemplar a colaboração de Morin com Jean Rouch na Paris dos anos 1960. (MORIN; ROUCH, 1961). Com câmera nas mãos, perguntavam a estudantes, operários, imigrantes: Você é feliz? Como você vive? Na qualidade de cinema-verdade, Crônica de um verão desvela a alma e a carne do gênero humano. É Antropologia no sentido mais amplo do termo, projeção-identificação, jogo-rito que combina uno e múltiplo, unidade e diversidade, particularidade e universalidade.

As pesquisas sobre os rumores coordenadas por Morin nos anos $60 \mathrm{em} \mathrm{seu}$ projeto sociológico são exemplos cabais de que é possível escutar a sociedade de outra maneira, que não seja por meio da análise das representações culturais que grupos e indivíduos fazem de si mesmos. O rumor de Orleans (1969) é exemplo disso. Na simpática cidade de Orleans, em maio de 1969, espalha-se o rumor de que seis donas de lojas de roupas femininas estão envolvidas com o tráfico de escravas brancas. Mulheres jovens, belas preferencialmente, que entram em butiques à procura de vestimentas, são sumariamente seqüestradas por homens do mal que as levam para lugares ermos. Drogadas e encapuçadas, são forçadas a se prostituírem sem nenhuma forma de pagamento. As proprietárias dessas lojas são judias. Além de supostas mentoras do tráfico de prostitutas, colaboram na construção de um canal subterrâneo que desemboca no rio Loire. Transportadas por barcos e até por estranhos submarinos a lugares escusos, essas supostas clientes se entregam a impensáveis rituais orgiásticos.

Naquela então pacata Orleans, não havia nenhum canal subterrâneo, nenhuma mulher havia sido drogada ou seqüestrada, nenhuma rede de prostituição montada. 
A cidade entra em pânico. Geralmente donos de estabelecimentos comerciais, os judeus são convertidos em bodes expiatórios, vítimas de preconceitos, racismos, exclusões. O imaginário de um rumor infundado havia criado o duplo vínculo entre eu e outro, tolerância e intolerância, bem e mal. A violência mimética se instala e, com ela, o preconceito contra judeus ganha corpo.

No transcorrer dos anos 70, o projeto de um Método entendido como estratégia e jamais como um conjunto frio de regras aplicado a objetos inertes adquire visibilidade com a publicação de $A$ natureza da natureza (MORIN, 1977). Os cinco volumes subseqüentes desse projeto de errância pelos territórios do conhecimento - A vida da vida, O conhecimento do conbecimento, As idéias, A bumanidade da bumanidade - a identidade bumana, Ética (MORIN, 1980, 1986, 1991, 2001, 2004)constituem uma viagem sem ponto de chegada, itinerário transversal por várias áreas do conhecimento, caminho que se faz ao andar, esboço hercúleo de modelizar a complexidade organizacional do humano.

Se algum objetivo deve ser buscado nesse meta ponto de vista, ele se expressa na profunda insatisfação com o paradigma do Ocidente que degenera o saber em concepções mutuantes e fragmentárias, cinde a cultura científica e a cultura das humanidades, descarta os paradoxos do espaço-tempo.

Incapaz de perceber a conjunção uno-múltiplo e realizar a unitas complex, que implica a unidade na complexidade e a complexidade na unidade, a barbárie do pensamento encontra seu berço esplêndido na organização universitária. Produz a alta cretinização, dada a dominância tecnoburocrática que invade o principal veículo de criação e recriação do saber; espetaculariza a baixa cretinização presente nos territórios da mídia e na maioria das instituições de fomento à pesquisa extasiadas com o progresso da tecnociência e da fragmentação.

Como a cultura, conceito-armadilha, a complexidade é idéia-problema. Não deve ser identificada a um ni ilismo imobilizador ou a uma irracionalidade que joga a razão na lata de lixo da história, mas como um ponto de partida, um fundamento que tece em conjunto, que religa o que está separado. Constitui uma revolução cognitiva que requer a reforma do pensamento sempre enfatizada por Morin.

As artes da imaginação sempre foram revolucionárias. Escritores como Balzac, Dostoiéviski, Musil, Machado, Pessoa, Calvino, Duras, esta última grande amiga de Edgar Morin, poetas como Hölderlin, Auden, Whitman, Lorca, Bishop, Plath, Drumond desferiram golpes irreversíveis nas certezas do racionalismo, pois em 
suas narrativas a separação razão-desrazão, real-imaginário não tem vez e nem lugar. Para esses protagonistas da ansiedade humana, a prática da complexidade é um ato criativo que prescinde de regras, métodos, projetos, como se ela fosse sempre inconsciente de sua própria grandeza de seus efeitos, de sua problemática.

Ao que tudo indica, a consciência moderna deixou de lado a multiplicidadediversidade contida na interconexão de imagens e materialidades, realidades e idealidades que compõem a pluralidade das esferas da vida. Esgotada pelo pensamento mutuante, precisa repensar-se a si própria, para que a crise dos paradigmas frutifique numa recomposição de todos os saberes planetários. Assumir esse ponto de vista como um projeto implica praticar ciência com consciência (MORIN, 1982), cultivar a auto-ética, praticar a sócio-ética, garantir a antropoética.

lmpossível estabelecer um receituário das regras do método complexo, tão a gosto do dispositivo científico, ou definir sua aplicabilidade imediata ao mundo da vida. Em primeiro lugar, torna-se imperativo superar a matriz sociocêntrica e igualmente androcêntrica das ditas ciências humanas. Mantê-la é aderir ao imperialismo cognitivo dominante, que produz reificações do social, determinações unilaterais, causalidades enregeladas. Se a cisão homem-natureza carece de qualquer fundamento ontológico, os saberes nunca são auto-suficientes. Bases da complexidade, a prática da conectividade e da transversalidade exigem que a razão se abra, o pensamento se reforme, a criatividade se desencadeie, o medo do erro se extinga, a revolta se explicite, a auto-ética contamine o eu e o outro.

Um teoria complexa dos sistemas bioculturais deve ser entendida nesse timbre. A noção de sistema não se reduz aqui a uma superposição de partes, na medida em que sua totalidade nunca se identifica a uma mera somatória de partes, e isso porque imprevisibilidades, instabilidades e bifurcações impedem que isso ocorra. O sistema é sempre uma unidade ambivalente, instável, aberta na qual parte e todo por vezes se associam, por outras não. Embrenhado no tetragrama ordem-desordem-interação-organização, o próprio sistema se auto-organiza, produz causas que produzem efeitos que produzem causas, inintencionalidades que se escondem por trás de intencionalidades planejadas, mitologias que se imiscuem com realidades concretas, lembranças indeléveis, memórias realçadas.

Acredito ser essa pulsão a totalidade da obra de Edgar Morin e concretiza as chamadas reorganizações genéticas de seu pensamento. A princípio, e sempre com as devidas cautelas que devem cercar transposições conceituais de um domínio ao 
outro, as contribuições advindas das teorias dos sistemas, da informação e da cibernética são incorporadas como fundamentais. A informação não se reduz a um rede na qual emissores e receptores trocam mensagens estatísticas advindas de canais específicos; é também memória voluntária e involuntária estocagem, tradição. Ainda é cedo para se construir agendas para o futuro que tomam como base a irreversibilidade das novas tecnologias da informação, das mídia-esferas, das infovias, da eventual espiritualidade das máquinas artificias, das simulações, dos ciberespaços, das clonagens humanas e, desse modo, passar a considerar essa parafernália tecno industrial como capaz de mimetizar o humano e dar nascimento ao pós-humano que prescinde de amor, poesia e sabedoria.

Os fundamentos da complexidade impõem a rejeicão de qualquer tipo de teleologia sobre os destinos do mundo. Mesmo com a internet que democratiza e dissemina noosferas para todo o planeta, ainda é apressado, otimista demais, prever se esses sistemas virtuais, que estão em todos os lugares e em nenhum lugar, substituirão a territorialidade dos estados-nações, o toque dos afetos, o olho no olho dos diálogos. O destino do sapiens-demens é obra aberta, rio majestoso como Morin considera, simultaneamente sereno e tempestuoso. A reorganização e a religação dos saberes são sempre biodegradáveis, redefinem-se a todo momento, fundam-se na dialogia, na recursividade e no holograma, operadores cognitivos a serem acionados em qualquer pesquisa, ensaio, tese, conferência.

O desafio está posto. Ele parece sinalizar a necessidade de civilizar as ideias, para que seja possível reorganizar o processo de conhecimento, dar novo sentido à tríade indivíduo-sociedade-espécie e, finalmente, perceber que sociedade, cultura, cerebralização são verso e reverso do processo da humanização. A co-presença das múltiplas expressões do imaginário e do real, da subjetividade e da objetividade, da razão e da desrazão dão corpo e sintonia às diversificações complexas de um processo histórico que, há milhões de anos, nada mais faz do que explicitar a unidualidade do sapiens-demens.

Situado nesse entre-dois, o homem expressa não apenas a trajetória da desordem sapiental, mas a dialogia e a recursividade entre o rígido e o transitório, o substantivo e o transcendente, a ordem e o ruído, a repetição e a criatividade. Nesse oceano tormentoso, o sapiens sapiens demens equilibra-se de modo instável, confrontado com desastres irremediáveis e horrores de toda ordem, inundado por fluxos de insignificância que atravessam o cotidiano, saturado de formatos pré-estabelecidos pela biopolítica dominante.

16 Somanlu, ano 8, n. 2, jul./dez. 2008 
Algo, porém, distingue Morin dos demais pensadores, expresso no vigor de suas explosões subjetivas, na intimidade de seus diários, nas revelações de suas origens judaicas, nas desavenças de sua família e, mais recentemente, nos sentimentos de perda ligados à morte de sua mulher, a saudosa Edwige, a quem presto a devida homenagem neste pequeno texto.

Intelectuais não costumam falar de si. Escondem suas identidades e duplos, tendo como álibi a assepsia de conceitos, teorias e métodos. Na maioria das vezes, diários, cartas, rascunhos são sempre disponibilizados após a morte, o que de certa forma propicia um certo grau de intocabilidade na personalidade comumente controvertida e contraditória de pensadores, sejam eles cientistas, romancistas ou poetas. Alguns poucos momentos da trajetória de Edgar podem ajudar a aclarar as reorganizações genéticas com as quais se deparou. Seleciono dois que considero paradigmáticos. No Diário da Califórnia (MORIN, 1970) exibe a curiosidade do estrangeiro que quer saber de tudo para, talvez, retornar a si mesmo de modo menos narcísico.

Esse parece ser o maior fruto das viagens, quaisquer que sejam elas. Despregar-se dos lugares intocáveis da casa original, desapegar-se dos objetos sacralizados da casa, dos livros que jazem nas estantes são as alavancas do descentramento psíquico e do desenraizamento subjetivo necessários para pensar sobre si mesmo e os outros e refletir sobre a unidualidade sapiental. Se reflexos no pensamento não podem ser determinados por viagens, não resta dúvida de que elas produzem reorganizações genéticas como Morin denomina esse conjunto de mutações que reorienta a existência, redeflne os afetos e amplia a sabedoria.

No Diário da China (MORIN,1992), publicado no Brasil em 2008, as utopias de um socialismo redentor se esvaem, como que contaminadas pelo espírito do tempo. Diante da mais antiga civilização do mundo, as brechas se petrificaram. A China havia sido objeto de um número especial da revista Arguments, editada com Cornelius Castoriadis e Claude Lefort, em número especial dedicado ao "grande timoneiro" Mao e seus propósitos revolucionários. Com esses dois fiéis companheiros, publicou Maio de 68-a brecha, um diagnóstico sobre as 'barricadas do desejo', cujos ecos repercutiram por aqui num Brasil ditatorial que vivia sob a tortura e a inumanidade.

Como um antropólogo em Marte, condoído no avião que o conduzia de Paris a Pequim pela morte do amigo Félix Guattari, não familiarizado com as dificuldades lingüísticas e sentidos que o cotidiano sempre oculta, é na China que Edgar busca 
outras significações nas fisionomias, odores, sabores, vestimentas, olhares, maneiras da mesa, estilos de comportamento, mesmo diante dos comandos do burocratismo socialista do então presidente Deng Xiaoping. Os chineses -- adverte Morin - modernizamse vertiginosamente e crêem nisso sem restrições. O que não sabem é que -assim como nós - encontram-se inseridos na aventura incerta, universal, damocleana comum a todos.

Alertas de Edgar Morin são sempre incisivos nesses sombrios tempos de barbárie. É urgente propor uma política de civilização que reconheça não apenas os valores das sociedades ocidentais, mas também, as virtudes das outras sociedades ditas periféricas. Os desafios que o século 21 apresenta ao Oriente e ao Ocidente requerem a construção de uma cidadania mundial. Para isso, torna-se prioritário regenerar as cidadanias locais e gerar uma cidadania mundial que religue as várias terras natais à Terra-Pátria, ensaio escrito em 1993.

Se a reforma da moral e da ética prevalecerem sobre a ganância da economia e a incapacidade da política, a regeneração civilizatória pode recalcar definitivamente a barbárie, trancafiá-Ia a sete chaves num castelo inexpugnável. A regeneração da TerraPátria não prega, porém, a extinção do estado-nação, mas uma ecologia ética que insere estados-nações em redes transacionais mais vastas e inclusivas, para que o direito de ingerência sobre indivíduos, etnias, classes, gêneros deixe de ser prerrogativa local de um governo, de um estado, de um partido.

A universalidade de valores cosmopolitas nunca é obtida pela soma ou subtração de interesses particulares, mas pela multiplicação das pulsões planetárias guiadas pelos quatro formatos da consciência: a antropológica, baseada na unidualidade do sapiensdemens, a telúrica, ilustrada pela indeterminação do sistema Terra; a ecológica substantivada pelo caráter auto-eco-organizador da biosfera e, finalmente, a consciência cosmológica, que recoloca o planeta numa pluralidade de estrelas e galáxias. A esses quatro caminhos, adicionariam as tomadas de consciência da ameaça damoclena, da perdição e do destino terrestres, recicladas pelo retorno do homem genérico, só que dessa vez saturado de subjetividade, afetividade, amor, desregramento.

A adesão a esses pressupostos advém de todos os horizontes do pensamento científicos, religiosos, literários, místicos, míticos, poéticos, orientais, ocidentais - que compõem a planetarização das relações do homens entre si e com os ecossistemas. Precisamos, porém, nos armar de "uma ardente paciência. Não estamos próximos da luta final, mas na luta inicial" (MORIN, 1993, p. 217). A reforma da educação exige

18 Somanlu, ano 8, n. 2, jul./dez. 2008 
intelectuais imbuídos na construção de uma ética de valores universais que contradiz relativismos e particularismos esclerosados e bate de frente na tecnoburocracia instalada nas ciências humanas. Auto-crítica permanente, auto-ética cotidiana, reorganização genética permanente, espírito livre e autônomo, subjetividade múltipla, êxtase amoroso, meditação sobre caminhos e descaminhos do sujeito, livre curso aos fluxos desejantes são propulsores desse meta ponto de vista.

A tarefa não se esgota por aí. É preciso caminhar por lugares reais - cidades sitiadas, universidades sucateadas, mundanidades escusas, sexualidades recalcadas - para que os dilemas sociais se mostrem como verdadeiramente são, mesmo que essa missão seja penosa, custosa, por vezes desestimulante. Encontramo-nos imprensados numa luta titânica entre forças dissociativas e associativas. Pequenos ensaios recentes têm procurado dar conta disso. Dentre eles, destaca-se $\mathrm{O}$ mundo moderno e a questão judaica (MORIN, 2006). O texto expõe as garras da intolerância cultural. Em junho de 2002, em conjunto com Daniele Sallenave e Sami Naïr, o Le Monde publica o artigo IsraelPalestina: o câncer. A associação Advogados sem fronteiras acusa os autores de apologia do anti-semitismo e apologia do terrorismo. Condenados em primeira instância, acabam absolvidos em julho de 2006, e a sentença obriga os acusadores ao pagamento de multa, cujo valor simbólico não condiz com a vilania das acusações. O fato em si exige de Edgar Morin mais um ajuste de contas consigo mesmo, um judeu marrano que sofreu na pele os efeitos da intolerância histórica e da incompreensão que grassa entre as culturas do mundo.

Mais que isso, o ensaio deixa claro que nosso destino planetário se debate entre dois modelos antagônicos de existência social, um instituído, marcado pelo poder político escuso, que espalha o mal-estar e pratica o bem-estar apenas para si mesmo; outro instituinte, que aciona fluxos de desejo advindos da porosidade da sociedade civil, como se fossem epifanias que advogam a sustentabilidade, a ética, a regeneração, a solidariedade. Apostar no segundo é o maior desafio que a complexidade tem pela frente, o que impõe o diálogo com outros estilos de pensamento e formas de ver o mundo. Não se trata de um empreendimento salvacionista, mas de um horizonte ético realista que recoloque a universalidade do humano como prioridade máxima. A ética da compreensão planetária ocupa papel de destaque nessa nova paideia, não como um elenco de proposições abstratas, mas "como atitude deliberada de todos aqueles que acreditam ainda ser possível sociedades democráticas se solidarizarem, mesmo com a aspereza do caminho e o desânimo dos caminhantes" (CARVALHO, 2003, 398). 
A presença de Edgar Morin no Brasil é constante, estimulante, desafiadora, mesmo que a Universidade não preste a devida atenção a suas idéias. Núcleos do pensamento complexo disseminam-se por toda parte, cada um com suas peculiaridades, mas todos sintonizados com os propósitos de uma ciência aberta e transdisciplinar. Homenagens, títulos de honoris-causa são expressão do reconhecimento da obra e do homem.

Três homenagens recentes marcaram minha vida: a primeira, por ocasião de seus 80 anos, no plenário da Unesco, em Paris, em julho de 2001. Em minha tímida saudação, exortei a importância de seu pensamento e a ressonância de suas obras por aqui nos tristes trópicos, em especial na Puc de São Paulo. Coube a minha colega e amiga Conceição Almeida, de Natal, Rio Grande do Norte, expressar com mais vigor meus sentimentos. Presenteou Edgar com um frasco de terracota da ilha de Marajó, um singelo objeto utilizado pelos moradores da floresta como um recurso simbólico para o sucesso de caçadas solitárias ou coletivas. Esse pequeno objeto - afirmou ela pode mágica e simbolicamente representar você: a fonte de um veneno vital, no qual reconhecemos a essência de uma ciência com consciência, um veneno do bem que nos faz sonhar acordados.

A segunda homenagem, também em Paris, em julho de 2006, na Maison de I'Amérique Latine, em seus 85 anos, cercada de amigos de toda parte do mundo, tinha o apoio da Multiversidade do mundo real, em Hermosillo, México, inspirada em Edgar Morin, um projeto de ensino e pesquisa ainda não concretizado. A festa transcorreu animada com mariachis entoando canções latinoamericanas. Edgar estava feliz por nos ter por perto, seus amigos, seguidores e, também, críticos de sua obra.

Ainda em Paris escrevi, rascunhei algumas palavras no calor das emoções do encontro.

Semelhantes no nome, sintonizados astrologicamente no signo de câncer, tenho com Edgar uma cumplicidade indefinível, uma admiração indescritível, uma identificação irresistível. Muito do que sou hoje tem a ver com suas idéias, ensinamentos, provocações. Talvez sejam essas as ressonâncias afetivas que ainda me animam a pensar em uma Antropologia verdadeiramente digna desse nome, a ser transmitida, com coragem e sem negociações às gerações do futuro, na Universidade e fora dela. (CARVALHO, 2006, 211). 
Finalmente a terceira, ocorrida na Puc de São Paulo, em seis de novembro de 2008. Era mais que necessário que a Universidade lhe outorgasse o título de honoris-causa. O tempo era escasso para os procedimentos burocráticos que a concessão de um título como esse exige. Aprovado em todas as instâncias acadêmicas, aproveitando uma breve estada de Edgar em Salvador e uma passagem meteórica por São Paulo, a celebração teve lugar no Tuca.

$\mathrm{Na}$ qualidade de proponente do título, coube a mim a saudação inicial. No teatro, com ausência de grande parte de professores e presença maciça de alunos e amigos, procurei ser breve e conciso. Dominado pela emoção, encerrei meu discurso afirmando o seguinte:

Tenho a convicção de que a PUC de São Paulo, palco de tantas lutas, esperanças e decepções se engrandece com o título agora outorgado a você. Sairemos todos daqui mais sintonizados com a ética da compreensão que você tanto valoriza, apostando na universalidade da cultura e na unidade do humano. (CARVALHO, 2008).

Igualmente emocionado, Edgar Morin agradeceu à Universidade. Em portunhol, confessou que, aos 87 anos, considera-se um aprendiz, um caminhante sem caminho, palavras do poeta espanhol Antonio Machado, que ele tanto admira e que expressa os múltiplos itinerários e desafios que o pensamento complexo ainda terá de enfrentar.

\section{Referências}

CARVALHO, Edgard de Assis. Edgar Morin, 85 años. IN: REYNAGA, Rubén (Org.). Em Homenaje al amigo Edgar Morin 85 años. Hermosillo, Multiversidad Mundo Real Edgar Morin, 2006. (mimeo.).

. Discurso de saudação a Edgar Morin na cerimônia de concessão do título de honoriscausa, outorgado pela PUC de São Paulo. 2008. (mimeo.).

MORIN, Edgar. L'homme et la mort. Paris: Corra, 1951.

Le cinéma ou l'homme imaginaire. Paris: Minuit, 1956. Edição portuguesa: O cinema ou o homem imaginário. Ensaio de Antropologia. Tradução António-Pedro Vasconcelos. Lisboa: Relógio d'água, 1997.

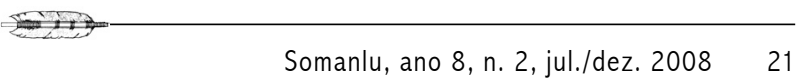


. La rumeur d'Orléans. Paris: Seuil, 1969.

MORIN, Edgar; ROUCH, Jean. Chronique d'un été. Paris; Argos Films, 1961. (DVD Vídeo Filmes, Crônica de um verão. Comentários de Eduardo Escorel, Eduardo Coutinho e Carlos Alberto Mattos, 85 min. São Paulo, 2007). . (colaboração com Claude Lefort e Cornelius Castoriadis). Mai 68: la brèche. Paris: Fayard, 1968.

. Journal de Californie. Paris: Seuil, 1970.

. La méthode I. La nature de la nature Paris: Seuil, 1977.

. La méthode II. La vie de la vie. Paris: Seuil, 1980.

MORIN, Edgar. La méthode III. La connaíssance de la connaissance. Paris: Seuil, 1986.

MORIN, Edgar. Journal de Chine (mimeo.) Edição brasileira: Diário da China. Tradução Edgard de Assis Carvalho. Porto Alegre: Sulina, 2007. (com a colaboração de Anne-Brigitte Kern). Terre-Patrie. Paris: Seuil, 1993. . La méthode IV. Les idées. Leur habitat, leur víe, leurs moeurs, leur organisation. Paris: Seuil, 1995.

MORIN, Edgar. La méthode V. L'humanité de l'humanité. L'identité humaine. Paris: Seuil, 2001.

. Le monde moderne et Ia question juive. Paris, Seuil, 2006. Edição brasileira: O mundo moderno e a questão judaica. Tradução Nícia Adan Bonatti. Rio de Janeiro: Bertrand Brasil, 2007.

22 Somanlu, ano 8, n. 2, jul./dez. 2008 